\title{
论 文
}

\section{印度谷螟实时荧光定量 PCR 内参基因的选择}

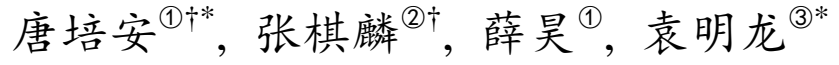 \\ (1) 南京财经大学食品科学与工程学院, 江苏省现代粮食流通与安全协同创新中心, 南京 210023 ; \\ (2) 南京大学生命科学学院, 演化发育生物学研究所, 南京 210023; \\ (3) 兰州大学草地农业科技学院, 草地农业生态系统国家重点实验室, 兰州 730020 \\ $\dagger$ 同等贡献 \\ * 联系人, E-mail: tangpeian@163.com; yuanml@1zu.edu.cn
}

收稿日期: 2016-05-11; 接受日期: 2016-08-04; 网络版发表日期: 2016-09-19

粮食公益性行业科研专项(批准号: 201413007-2)、国家科技支撑计划(批准号: 2013BAD17B01)、国家自然科学基金(批准号: 31000828)和 江苏省高校优势学科建设工程资助

\begin{abstract}
摘要 实时荧光定量 PCR(qRT-PCR)是研究基因表达的重要手段之一, 而选择合适的内参基因是获得可靠研 究结果的基础. 本研究以世界性分布的重要仓储害虫印度谷蛽(Plodia interpunctella) 为研究对象, 旨在䇻选出该 虫不同发育阶段及不同品系 qRT-PCR 的最适内参基因, 并利用两个独立软件(geNorm 和 NormFinder)对 8 个备选 内参基因的表达稳定性进行了评价. 结果表明, 不同发育阶段最稳定表达的内参基因为 $E f 1 \alpha$ ，而不同品系最 稳定的是 $\beta$-Actin 和 Efl $\alpha$. 利用篇选到的 Efl $\alpha, \beta$-Actin 及两者组合对目标基因(过氧化物酶POD)进行标准化，印 度谷蛽不同品系间的 $P O D$ 基因表达量存在显著差异, 而以稳定性最差的 $S D$ 作为内参时, 不同品系间 $P O D$ 的相 对表达量并无显著差异. 这表明, 在开展 qRT-PCR 研究时评价内参基因的稳定性非常必要, 且基于篎选到的最 佳基因作为内参时, 才能准确获得目标基因的相对表达水平. 这些结果将有助于更好地研究印度谷蛽发育及品 系特异相关基因的功能，并为篮选印度谷蛽在其他条件下的最适内参基因提供参考.
\end{abstract}

关键词印度谷蛽, 仓储害虫, 实时定量 PCR, 基因表达, 内参基因, 稳定性评价

实时苂光定量 PCR(quantitative real time PCR, qRT-PCR)技术是探索不同实验条件下目标基因表达 情况的重要工具, 近年来已广泛应用在遗传、信号传 导及生物进化等方面. 目前, 虽然诸如半定量 PCR, Northern 杂交及 RNA 高通量测序等也用来研究基因 表达，但是这些技术都存在步骤复杂、灵敏度低和成 本较高等不足 ${ }^{[1]}$. 然而, qRT-PCR 的成功与可靠结果
的获得，高度依赖于所选内参基因的可靠性；选择合 适的内参基因，可有效消除起始 RNA 质量和样品间 差异等因素的影响 ${ }^{[2,3]}$. 理论上, 理想的内参基因应 该是不受任何实验条件和物种特异性的影响, 但目 前在 qRT-PCR 中广泛使用的内参基因, 如延伸因子 $1 \alpha($ elongation factor $1 \alpha, E f l \alpha)$ 、微管蛋白 $\beta(\beta$-Tubulin $) 、 18 \mathrm{~S}$ 核糖体 RNA(18S)等，在不同条件

引用格式: 唐培安, 张棋麟, 薛吴, 等. 印度谷螟实时苂光定量 PCR 内参基因的选择. 中国科学: 生命科学, 2016, 46: 1201-1209 Tang P A, Zhang Q L, Xue H, et al. Selection of reference genes in quantitative real-time PCR of Plodia interpunctella (Lepidoptera: Pyralidae). Sci Sin Vitae, 2016, 46: 1201-1209, doi: 10.1360/N052016-00176 
下其表达水平并不总是稳定的 ${ }^{[4 ~ 9]}$. 这种现象主要是 由于所选择的内参基因在转录和代谢过程中也扮演 重要角色 ${ }^{[10,11]}$, 且使用单个内参基因对目标基因的 表达量进行标准化时, 往往显得不够充分 ${ }^{[12 ~ 14]}$.

目前, 对昆虫内参基因的䇻选已开展了大量研 究, 主要涉及各种非生物或生物胁迫下(如不同发育 阶段、组织、微生物感染和化学物刺激等)的沙漠蝗 (Schistocerca gregaria $)^{[15]}$ 、黑腹果蝇 (Drosophila melanogaster $)^{[16]}$ 、吉丁虫(Agrilus planipennis) ${ }^{[17]}$ 、小 菜蛾 (Plutella xylostella $)^{[18]}$ 、桔小食蝇 (Bactrocera dorsalis $)^{[19]}$ 、烟粉垕 (Bemisia tabaci) ${ }^{[20]}$ 、红火蚁

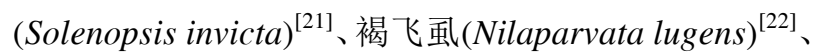
瓜食蝇 (Bactrocera cucurbitae) ${ }^{[23]}$ 、大螟 (Sesamia inferens) $)^{[24]}$ 、赤拟谷盜 (Tribolium castaneum) ${ }^{[25]}$ 和家蚕 (Bombyx mori) $)^{[26]}$ 等. 这些研究结果均显示, 所有内 参基因在不同实验条件下以及不同物种间的表达稳 定性呈剧烈变化. 特别是, 即使在亲缘关系较近的 4 种鳞翅目昆虫中也未发现能够通用的内参基因 ${ }^{[27]}$. 因此, 针对不同的物种及各种实验条件, 有必要篮选 适于其目的基因 qRT-PCR 分析的内参基因.

印度谷螟 (Plodia interpunctella) 是粮食储藏期间 最为常见的害虫之一, 世界性分布, 而且其还包含大 量的过敏原, 严重威胁农业生产和人类健康 ${ }^{[28]}$. 迄今 为止, 印度谷螟的全基因组测序还没有完成, 但是近 年来随着人们对其性染色体剂量补偿机制的关注, 雌雄印度谷螟成虫的转录组已经被测序组装 ${ }^{[29]}$. 最 近, 本课题组也完成了印度谷蛽不同虫态的总转录 组, 并采用数字表达谱技术研究了卵、幼虫、蛹和成 虫的基因表达. 借助于这些日益丰富的基因组资源, 建立可靠的 qRT-PCR 实验体系, 对于进一步开展印 度谷螟功能基因组学研究尤为重要. 目前, 昆虫内参 基因稳定性评估主要是集中在作物、果树和园艺害 虫，而仓储害虫的内参基因评估还很少有报道. 刘金 泊等人 ${ }^{[25]}$ 利用 geNorm 和 NormFinder 对磷化氢诱导 下赤拟谷盗的内参基因稳定性进行了评估, 认为 $R P S l 8$ 和 $R P L I 3 a$ 最适合作为该条件下的内参基因. 但是, 赤拟谷盗(鞘翅目)和印度谷螟(鳞翅目)物种差 异较大, 而且以往研究实验条件相对单一(仅有一种 实验处理). 因此, 基于这些研究结果选择印度谷蛽 的内参基因还具有一定的参考局限性. 综上所述, 在 不同实验条件下对更多的仓储害虫系统全面地进行 更大数量的内参基因稳定性评估是有必要的.
本研究旨在系统全面地鉴别印度谷螟不同品系 和不同发育阶段可靠的内参基因，并推荐准确的标 准化内参基因数目. 选择琥珀酸脱氢酶 (succinate dehydrogenase, $S D) 、 E f 1 \alpha$ 、微管蛋白 $\gamma(\gamma$-Tubulin)、 $\beta$-Tubulin、细胞色素氧化酶 (cytochrome oxidase, $C O X)$ 、细胞周期蛋白 $\mathrm{A}(\operatorname{Cyclin} A)$ 、肌动蛋白 $\beta(\beta-A c t i \mathrm{n})$ 和 $18 S$ 等 8 种基因 ${ }^{[30 ~ 32]}$ 作为备选内参基因, 利用 qRT-PCR 技术开展这 8 种基因在印度谷螟不同发育 阶段和不同品系中的基因表达分析，并利用 geNorm $^{[33]}$ 和 NormFinder ${ }^{[34]}$ 软件对这些备选内参基因 进行稳定性评价, 且基于 geNorm 的分析结果确定不 同实验条件下能获得准确定量结果的标准化因子数 目. 此外, 以过氧化物酶基因(peroxidase, $P O D$ )作为 目标基因, 根据其在印度谷蛽不同品系中的表达谱, 证实篎选到的最佳内参基因的可靠性. 研究结果将 为印度谷螟 qRT-PCR 内参基因的选择提供可靠的指 导, 有助于后续该虫功能基因组学的研究, 也为其他 仓储害虫内参基因的选择提供参考和补充.

\section{1 材料与方法}

\section{1 印度谷蛽的采集与室内饲养}

印度谷蛽采自江苏省吴江市, 实验室人工培养箱 培养 20 代以上，培养条件为温度 $(30 \pm 0.5)^{\circ} \mathrm{C}$ 、湿度 $70 \%$ 80\%、黑暗条件. 不同发育阶段样本: 幼虫饲养 于 $17.5 \mathrm{~cm} \times 12.5 \mathrm{~cm} \times 13.5 \mathrm{~cm}$ 的塑料盒中, 待其羽化后 将成虫雌雄各半置于 $50 \mathrm{~mL}$ 烧杯中产卵, 将虫卵置于 直径 $2 \mathrm{~cm}$ 的虫笼中饲养, 定期观察其发育情况, 取龄 期一致的印度谷蛽作为试验材料. 不同品系样本: 分 别为长期食用饲料中含有 $2 \%$ 转 Bacillus thuringiensis $(\mathrm{Bt})$ 基因稻谷的抗性品系(1 年以上), 食用 转 $\mathrm{Bt}$ 基因稻谷 $48 \mathrm{~h}$ 的胁迫品系以及从未食用过转 $\mathrm{Bt}$ 基因稻谷的敏感品系(与不同发育阶段中的幼虫相同).

\section{2 试验方法}

(1) 样品制备. 分别挑选印度谷螟卵、三龄幼 虫、蛹和成虫等 4 个发育阶段以及 $2 \%$ 抗性品系与胁 迫品系三龄幼虫，依据试剂盒说明书提取各样本的 总 RNA.

(2) 总 RNA 提取和 cDNA 合成. 除卵使用 RNeasy Plus Micro Kit(Qiagen, 德国)外，其余总 RNA 的提取均使用 RNeasy Plus Universal Mini 
Kit(Qiagen). 总 RNA 的完整性采用 $1 \%$ 的琼脂糖凝胶 电泳进行检测, 并使用核酸浓度测定仪 (Eppendorf, 德国)检测其浓度和纯度. $A_{260} / A_{280}$ 值在 1.8 2.0 的样 品才被用于下游实验. 以 $1 \sim 5 \mu \mathrm{g}$ 的总 RNA 和 oligo $(\mathrm{dT})_{18}$ 特异引物, 按照 PrimeScript II cDNA synthesis $\operatorname{Kit}(\mathrm{TaKaRa}$, 日本) 说明书进行第一链 cDNA 的合成, 并储存于 $-20^{\circ} \mathrm{C}$. 使用前, 将储存的 cDNA 母液用无 RNA 酶水溶解至浓度 $100 \mathrm{ng} / \mu \mathrm{L}$ 以用 于后续实验.

(3) 内参基因选择、引物设计和扩增效率测试. 采用基于 Primer 3.0(http://frodo.wi.mit.edu/primer3/) 对 8 个备选内参基因和 1 个目标基因进行了引物设 计, 引物的详细信息见表 1. 通过 $1.5 \%$ 的琼脂糖凝胶 电泳, 证实所有基因引物的扩增特异性. 所有的 cDNA 样品各等量取一部分, 混合成一个总的 cDNA 池, 进行 4 倍稀释, 共设 5 个浓度梯度, 并分别对以 上 9 个基因进行 qRT-PCR, 构建标准曲线, 根据公式 $\mathrm{E}(\%)=\left(10^{(-1 / \text { slope })}-1\right) \times 100$ 计算扩增效率 ${ }^{[6]}$.

(4) 实时荧光定量 PCR 分析. qRT-PCR 分析是 通过 ABI 7300(Applied Biosystems, 美国)完成. cDNA 的扩增是以 QuantiFast SYBR Green PCR Kit(Qiagen)为基础, 在 96-well 孔 PCR 板上完成. 反 应体系总共 $20 \mu \mathrm{L}$, 包括: $1 \mu \mathrm{L}$ (大约 $100 \mathrm{ng}$ )cDNA, 正 反向引物各 $1 \mu \mathrm{L}\left(10 \mu \mathrm{mol} \mathrm{L} \mathrm{L}^{-1}\right), 10 \mu \mathrm{L}$ 的 $2 \times \mathrm{SYBR}$ Green 混合反应液和 $7 \mu \mathrm{L}$ 无 RNA 酶水. PCR 反应条 件: $95^{\circ} \mathrm{C}$ 预变性 $60 \mathrm{~s}$, 接下来 $95^{\circ} \mathrm{C}, 10 \mathrm{~s}, 57^{\circ} \mathrm{C}, 30 \mathrm{~s}$, $72^{\circ} \mathrm{C}, 35 \mathrm{~s}$, 共 40 个循环. 反应结束后, 确认实时 qRT-PCR 反应的扩增曲线和熔解曲线. 未加模板的 反应体系作为阴性对照, 用以确认模板扩增的特异 性. 每个反应重复 3 次.

(5) 数据处理和分析. 首先获得每个样品中每 个基因的平均 $C_{\mathrm{t}}$ 值, 利用 geNorm 和 NormFinder 软 件对不同发育阶段和不同品系内参基因的表达稳定 性分别进行评价. geNorm 主要通过分析基因在不同 样品中的表达稳定性 $(M)$ 来确定最稳定的基因, $M$ 值 越大, 稳定性越差. 反之, 稳定性越好. 在输入数据 时需要将原始 $C_{\mathrm{t}}$ 值经过 $2^{\left(-\Delta C_{\mathrm{t}}\right)}$ 变换 ${ }^{[33]}$. 在基因表达分 析中, 为减少实验误差, 通常需要使用 2 个及以上的 内参基因对目的基因进行校正，从而获得更加准确 的结果 ${ }^{[33]}$. geNorm 软件通过计算内参基因的配对差 异系数 $\left(V_{n / n+1}\right)$, 来确定合适的内参基因数目 ( $V$ 值).
程序默认 $V$ 值的阈值为 0.15 , 即如果 $V_{n / n+1}$ 首次小于 0.15 , 则说明候选内参基因中有 $n$ 个适合作为 qRT-PCR 的内参基因, 没必要引入第 $(n+1)$ 个. NormFinder 根据 $C_{\mathrm{t}}$ 值(经过 $2^{\left(-\Delta C_{\mathrm{t}}\right)}$ 变换), 结合组内方 差与组间方差计算出稳定值, 并根据稳定值的大小 对内参基因的稳定性进行评价 ${ }^{[34]}$. 稳定值越小, 该内 参基因越稳定; 反之, 越不稳定. 相对表达量的计算 方法依据 $2^{-\Delta \Delta C_{\mathrm{t}}}$ 原理 ${ }^{[35]}$, 并用 IBM SPSS 统计软件(版 本 22)中的 ANOVA 的单尾检验观察各处理间差异显 著性.

\section{2 结果与分析}

\section{1 实时定量 PCR 分析中基因的表达水平及引物 扩增效率}

8 个候选内参基因的标准曲线决定系数 $R^{2}$ 变化 范围是 0.984 0.999, 扩增效率在 90\% 120\%, 且熔解 曲线皆为单峰, 说明引物无非特异性扩增(表 1).

平均 $C_{\mathrm{t}}$ 值和其标准差用于描述基因的表达水平. 8 个备选内参基因中, $18 S$ 的 $C_{\mathrm{t}}$ 值最小, 表达丰度最 高; $\beta$-Actin, $18 S$ 和 Cyclin $A$ 等 3 个基因的 $C_{\mathrm{t}}$ 值变化范 围较大, 而 $\beta$-Tubulin 和 $\gamma$-Tubulin 的 $C_{\mathrm{t}}$ 值变化范围相 对较小(图 1). 可见, 不同基因的表达谱存在差异性, 且同一基因均存在不同程度的变异性.

\section{2 基因稳定性分析}

（1）不同发育阶段中的稳定性分析. 通过两种 独立的分析软件(geNorm 和 NormFinder), 分析了 8 个备选内参基因的表达稳定性(图 2A 和表 2). geNorm 的分析结果表明, 8 个内参基因在不同发育阶段的 $M$ 值由低到高分别为: $S D=E f 1 \alpha, \gamma$-Tubulin, $\beta$-Tubulin, CO, Cyclin A, $\beta$-Actin 和 $18 S$. 因此, 表达稳定性最高 的是 $S D$ 和 $E f 1 \alpha$, 而 $18 S$ 具有最大的表达变化程度. NormFinder 的分析结果表明, 最稳定的是 $E f l \alpha$, 接 下来依次为 $\gamma$-Tubulin, $\beta$-Tubulin, SD, CO, $\beta$-Actin 和 Cyclin A, 最不稳定的仍为 $18 S$. 由此可见, geNorm 中 最稳定的两个备选内参基因是 $S D$ 和 $E f 1 \alpha$, 在 NormFinder 的分析中也处于前 4 的稳定水平, 且两种 算法呈现的前 4 名备选内参基因种类完全一致, 即两 个软件都推荐 $E f 1 \alpha$ 为最稳定的备选内参基因. $18 S$ 在 两种软件的分析中均是最不稳定的备选内参基因. 
表 1 苂光定量引物信息

\begin{tabular}{|c|c|c|c|c|c|}
\hline 基因名 & GeneBank 登录号 & 引物序列 $\left(5^{\prime}-3^{\prime}\right)$ & 产物大小 (bp) & 相关系数 $\left(R^{2}\right)$ & 扩增效率(\%) \\
\hline$P O D$ & SRP051571 & $\begin{array}{l}\text { CGAGCAGTTCTACAGGACCA } \\
\text { GTGTCTCAGGTTCGAATGCC }\end{array}$ & 179 & - & - \\
\hline$S D$ & SRP051571 & $\begin{array}{l}\text { TCCAGCACACCCACAATAGT } \\
\text { CAGCTTGTTAGGCAGCACAA }\end{array}$ & 225 & 0.995 & 102.2 \\
\hline$E f 1 \alpha$ & SRP051571 & $\begin{array}{c}\text { CGTCAACAAGATGGACGACC } \\
\text { GCCTTGTCCTGTTTGTCCAG }\end{array}$ & 151 & 0.999 & 111.9 \\
\hline$\gamma$-Tubulin & SRP051571 & $\begin{array}{l}\text { CCCTTCTTCTGGCTCTGTCA } \\
\text { TCTGACTGGATGGCTGTTGT }\end{array}$ & 180 & 0.997 & 104.7 \\
\hline$\beta$-Actin & SRP051571 & $\begin{array}{l}\text { ATCTGGCACCACACGTTCTA } \\
\text { GCTTGAATCGCCACGTACAT }\end{array}$ & 161 & 0.984 & 110.3 \\
\hline$\beta$-Tubulin & SRP051571 & $\begin{array}{l}\text { AAGTTGCTGCGTTGGTAGTG } \\
\text { CTTCTCCATGTCGTCCCAGT }\end{array}$ & 242 & 0.993 & 119.2 \\
\hline $\mathrm{CO}$ & JX509837 & $\begin{array}{l}\text { TCGAGCAGAATTAGGTACCCC } \\
\text { GGGAAAGCTATATCTGGGGCT }\end{array}$ & 220 & 0.989 & 108.3 \\
\hline Cyclin A & AY388625 & $\begin{array}{c}\text { ACAGCAAAGACTGACCGAGA } \\
\text { TACTCGTCACACACCTCCAC }\end{array}$ & 185 & 0.983 & 110 \\
\hline $18 S$ & KJ836335 & $\begin{array}{l}\text { TTCACCGACGATATGCTCCG } \\
\text { ATTGGAGGGCAAGTCTGGTG }\end{array}$ & 165 & 0.996 & 110.4 \\
\hline
\end{tabular}

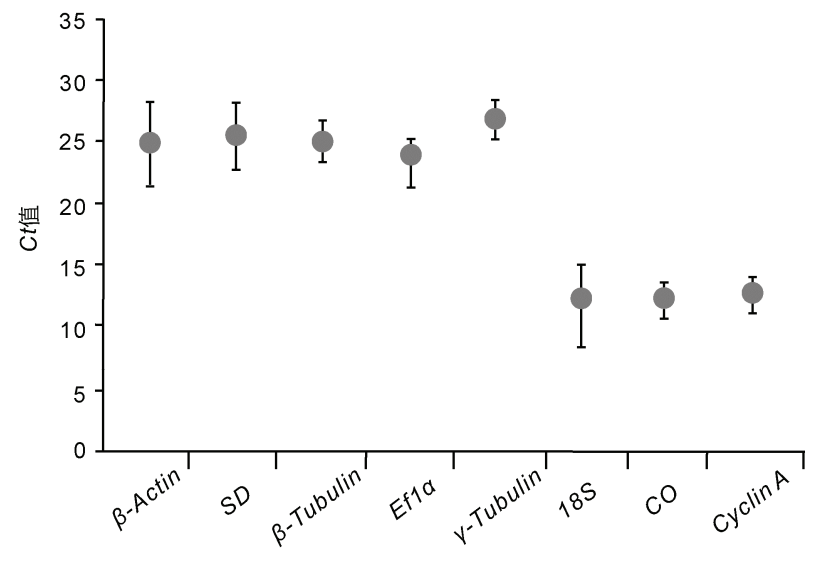

图 1 印度谷蛽各候选基因的表达水平

可见, 两种软件结果高度一致, 表明预测结果准确.

为了证实用于目标基因标准化最适合的内参基 因数目(标准化因子数), 利用 geNorm 分析了 $V_{n / n+1}$. 如果 $V_{n / n+1}$ 首次低于 0.15 (默认阈值)或者呈现出最小 的值(最小值情况下使用的标准化因子最少数目需 $\geqslant$ $3)$, 则对应的基因数目 $(n)$ 适合作为最适的标准化因 子 ${ }^{[33]}$. 由差异系数柱状图可知(图 3), 不同发育阶段 中差异系数均大于 0.15 且 $V_{2 / 3}$ 为最小的值. 因此, 可 结合 3 个最稳定的内参基因( SD, Efl $\alpha$ 和 $\gamma$-Tubulin) 作 为标准化因子进行印度谷螟不同发育阶段的 qRT-PCR 分析.

(2) 不同品系中的稳定性分析. 针对不同品系
的印度谷螟, 按照上述方法对 8 个备选内参基因的表 达情况进行了分析(图 2C 和表 2). geNorm 分析结果显 示, 不同品系的备选内参基因的表达稳定性排序依 次为 $\beta$-Actin $=$ Efl $\alpha>\gamma$-Tubulin $>\beta$-tublin $>$ Cyclin $A>C O>$ $18 S>S D$. 可见, $\beta$-Actin 和 Efl $\alpha$ 为最稳定的内参基因, 而 $18 S$ 和 $S D$ 表达最不稳定. NormFinder 分析结果表 明, 8 个内参基因的稳定性排序为 Efl $\alpha=\beta$-Actin $>$ $\gamma$-Tubulin $>\beta$-Tubulin $>$ Cyclin $A>C O>18 S>S D$. 两种分 析均支持 Efl $\alpha$ 和 $\beta$-Actin 是表达最稳定的内参基因, 而 $18 S$ 和 $S D$ 最不稳定. geNorm 的配对变异分析表明, $V_{2 / 3}$ 值首次低于 0.15 (图 3). 因此, 最适标准化因子数 是 2 , 最适合的内参基因为 $\beta$-Actin 与 Efl $\alpha$.

通过对 8 个备选内参基因在印度谷蚯不同条件 下(不同发育阶段和品系间)的稳定性评估，发现 Efl $\alpha, \gamma$-Tubulin, $\beta$-Tubulin 的表达水平在两种实验条 件下均具有较好的稳定性, 其中 Efl $\alpha$ 始终是最稳定 的备选内参基因. 虽然 geNorm 分析显示, $18 \mathrm{~S}$ 在印度 谷蛽不同品系间没有最大的稳定值(最小的稳定性), 但是其稳定性也处于所有 8 备选内参基因中的第 7 位. 因此, $18 \mathrm{~S}$ 在印度谷蛽不同实验条件下的表达水 平总表现出最差的稳定性.

\section{3 内参基因稳定性验证}

为验证内参基因稳定性评价结果的可靠性, 对 印度谷蛽不同品系的 POD 基因进行 qRT-PCR 分析. 

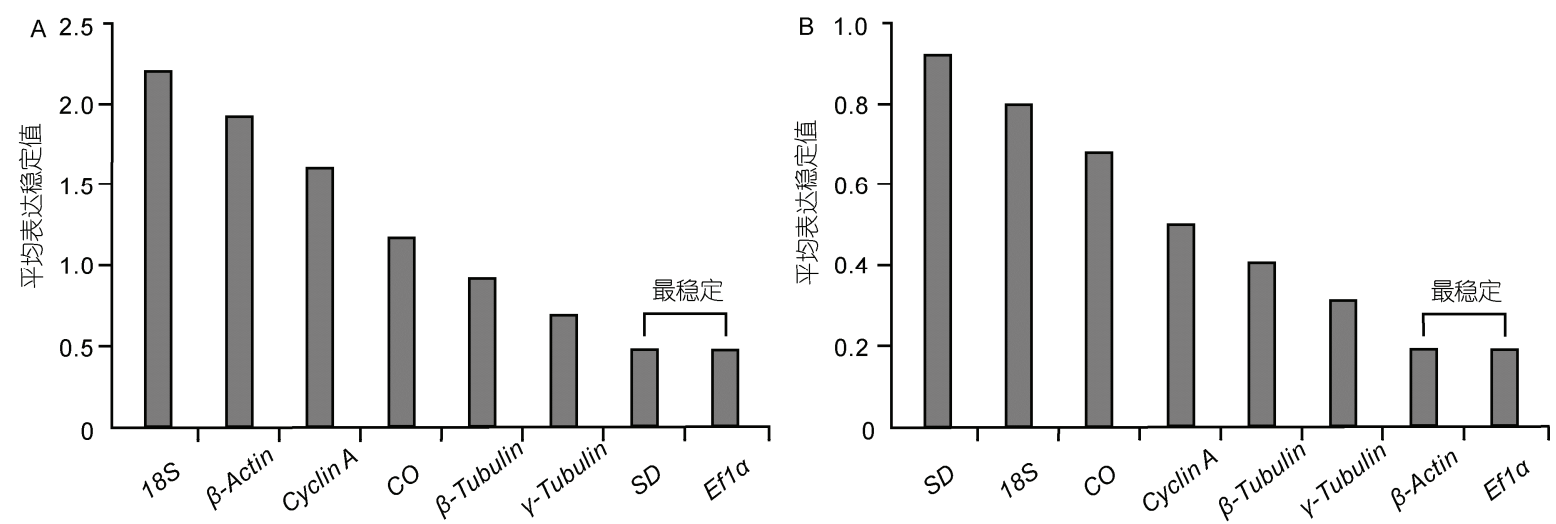

图 2 geNorm 软件对印度谷蛽不同发育阶段(A)和品系(B)内参基因表达稳定性排名

表 2 备选内参基因在印度谷蛽不同发育阶段及不同品系条件下 NormFinder 的稳定性评价结果

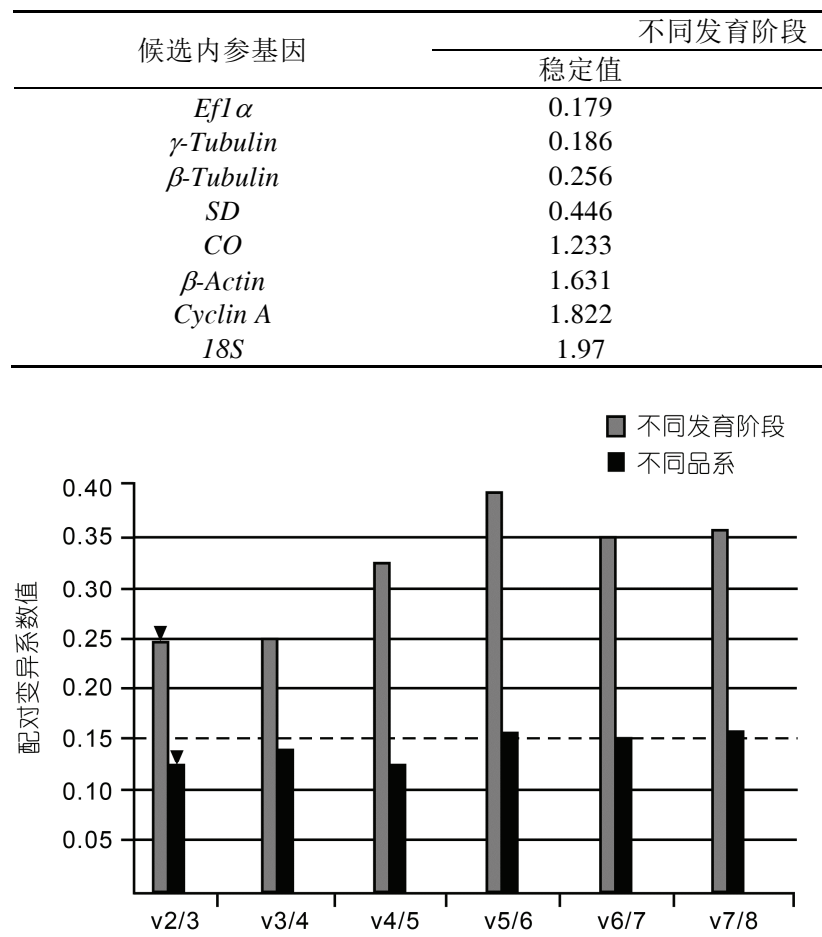

图 3 利用 geNorm 评价印度谷蛽不同发育阶段和品系中 内参基因的最适数目

$\boldsymbol{\nabla}$ : 标准化需要的内参基因数目

选择印度谷蛽不同品系中稳定性最好的 Efl $\alpha$, $\beta$-Actin 及两者的组合(最优标准化因子组合), 以及稳 定性较差的 $S D$. 结果显示, 以 $\beta$-Actin, Efl $\alpha$ 以及两者 组合分别作为目标基因的标准化因子时, $2 \%$ 转 $\mathrm{Bt}$ 基 因稻谷饲养和 $\mathrm{Bt}$ 胁迫的印度谷螟 $P O D$ 相对表达量显 著高于敏感品系, 且 Bt 胁迫品系也显著高于 $2 \%$ 转 Bt 基因稻谷饲养品系及敏感品系(图 4)。这表明，印

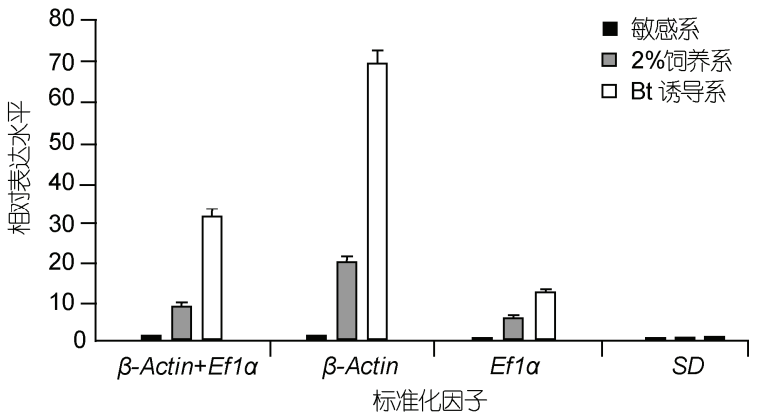

图 4 采用不同标准化因子的印度谷蛽不同品系过氧化物 酶基因 $P O D$ 的表达水平

度谷蛽 $P O D$ 在 $\mathrm{Bt}$ 毒蛋白胁迫条件下, 表达水平响应 明显，且随着喂食印度谷蛽的稻谷中 Bt 毒蛋白含量的 增加，其表达量显著上调. 而以稳定性最差的 $S D$ 作为 内参时, 3 个品系 $P O D$ 的相对表达量并无显著差异, 且表达量趋势不明显，完全扰乱了基于稳定内参基因 所获得的 $P O D$ 在 $\mathrm{Bt}$ 毒蛋白压力增加下的表达模式.

\section{3 讨论}

通过 qRT-PCR 研究目标基因的表达模式，是研 
究昆虫遗传、发育及进化等问题的重要思路. 内参基 因的应用, 是解决 qRT-PCR 过程中目标基因表达结 果标准化最合理有效的方式 ${ }^{[37]}$. 本研究首次评价了 世界性重要仓储害虫印度谷蛽在不同发育阶段及不 同饲喂食物条件下内参基因的稳定性. 结果表明, 在 同一实验条件下, 两种评价方法对 8 个备选内参基因 的评估结果具有高度一致性. 例如, 在印度谷螟不同 发育阶段或不同品系中, geNorm 和 NormFinder 的分 析结果显示的排名前 3 的最稳定备选内参基因有 $2 / 3$ 甚至全部都是完全一致的, 对于最不稳定的备选内 参基因选择结果基本一致(都为 $18 \mathrm{~S}$, 除了不同品系 中 geNorm 显示其稳定性为倒数第 2). 当然两种软件 的评价结果中也存在差异性, 这可能是由于不同的 算法导致的, 这种情况在其他内参基因评价的报道 中普遍存在 ${ }^{[37,38]}$. 印度谷螟不同实验条件下的最适 内参基因都是 $E f l \alpha$, 在脊椎动物的内参评估研究中, 显示其在受不同病原物刺激的黑鲇(Dicentrarchus labrax) 肠道内能稳定表达 ${ }^{[39]}$, 而在昆虫的内参基因 评估中, 报道 Efl $\alpha$ 在大蛽不同发育阶段稳定表达 ${ }^{[24]}$; 在小菜蛾不同发育阶段、组织和品系中也是如此 ${ }^{[18]}$. 因为大螟、小菜蛾与印度谷蛽同属于鳞翅目, 暗示了 该基因在不同鳞翅目昆虫发育阶段中稳定表达是一 种普遍现象. 此外, 对 $\mathrm{Bt}$ 毒素诱导下的小菜蛾(鳞翅 目)qRT-PCR 最适内参研究中, Efl $\alpha$ 也是被推荐的最 稳定内参, 而本研究也显示在用含不同 Bt 毒素量的 稻谷饲喂印度谷蛽条件下, $E f 1 \alpha$ 的稳定性在 8 个备选 内参基因中排名第一. 因此, 以后开展鳞翅目昆虫发 育生物学、功能基因组学和分子生态学等研究或者篮 选这些条件下的最适内参基因时, 应重点考虑 Efl $\alpha$. 但是, EfI $\alpha$ 在病毒感染的稻飞闽(半翅目)中 ${ }^{[22]}$, 表现 出最差的表达稳定性. 因此, 在不同实验条件下, 以 往普遍适用的内参基因可能会表现出较大的表达稳 定性差异, 在对目标基因标准化处理前都应证实所 选内参的稳定性.

符伟等人 ${ }^{[40]}$ 报道了在 $\mathrm{Bt}$ 毒素诱导下的小菜蛾 qRT-PCR 最适内参, geNorm 软件推荐 $\beta$-Actin 为较为 稳定的内参基因(稳定性排第 2). 本研究中 $\beta$-Actin 在 印度谷蛽不同发育阶段和不同品系比较中稳定性都 较好(稳定性至少前 4), 表明 $\beta$-Actin 虽在昆虫不同实 验条件下稳定性变化较大, 但仍处于较稳定的表达 水平. 因此, 以后的昆虫 qRT-PCR 研究可以考虑使
用 $\beta$-Actin. 有趣的是, $S D$ 在印度谷螟的两种不同实验 条件下, geNorm 分析显示其稳定性状态差异较大, 而 NormFinde 则未显示有如此大的差异. 当然这些变 化也恰恰说明了该基因稳定性变化对评估内参基因 的不同算法敏感度较高, 以及潜在的表达不稳定性. 目前, 对于 $S D$ 的稳定性评估几乎未见研究, 仅有周 世豪等人 ${ }^{[23]}$ 报道其在高温胁迫下的瓜食蝇中, 所有 评估软件都推荐其为最稳定的内参基因. 因此, $S D$ 表 达稳定性的广谱性可能较低. 对于类似备选内参基 因，在使用前应使用更多的软件对其进行稳定性评 估, 否则建议在 qRT-PCR 时对其不予考虑. $18 \mathrm{~S}$ 是目 前鳞翅目昆虫内参基因稳定性评价中使用频率最高 的基因之一, 以前研究报道了 $18 \mathrm{~S}$ 在所有备选内参基 因中表达丰度最高, 例如, 不同浓度杀虫剂胁迫下的 烟粉虫, 不同发育阶段、组织和品系下的小菜蛾, 这 与在印度谷蛽中研究结果一致, 表明 $18 \mathrm{~S}$ 广泛参与了 生物体的生理生化功能, 其在昆虫生命过程中扮演 重要角色. 当然, 这类基因的表达水平变化程度一般 较高. 本研究也发现, $18 \mathrm{~S}$ 在印度谷螟不同实验条件 下及采用不同软件评价时, 表现为极不稳定性, 这与 其他昆虫内参基因稳定性评估的结果一致 ${ }^{[40,41]}$. 因 此, 在印度谷螟 qRT-PCR 的试验中应避免 $18 \mathrm{~S}$ 作为 内参基因.

本研究结果发现，内参基因在不同发育阶段与 不同品系之间表达量差异显著, 稳定性差异较大, 这 证明了不同组织、细胞以及不同条件下内参基因的表 达水平存在差异 ${ }^{[42]}$. Olsvik 等人 ${ }^{[43]}$ 研究认为, 选用单 一内参基因研究基因表达的变化, 定量结果中误差 最多达到 3 倍以上, 故建议应选定多个内参并进行几 何平均以准确地标准化数据, 从而引入了标准化因 子配对变异系数 $\mathrm{V}^{[44]}$. 吴学友 ${ }^{[45]}$ 研究发现, 印度谷蛽 幼虫在进食转 $\mathrm{Bt}$ 基因稻谷后 $P O D$ 酶活性显著升高, 推测可知印度谷螟在进食转基因稻谷后 $P O D$ 基因表 达量升高, 以清除 $\mathrm{Bt}$ 蛋白代谢产生的有害物质. 短 时间进食可能会引起 $P O D$ 表达量的激增, 长期用 $2 \%$ 的转 $\mathrm{Bt}$ 稻谷饲养的印度谷蛽体内 $P O D$ 表达量会处于 一个较高但相对平稳的水平. 因此, 以稳定性较高的 $\beta$-Actin, Efl $\alpha$ 以及二者组合作为内参得到的结果与前 面的研究结果一致, 证实了所选内参基因的准确性. 而以稳定性较差的 $S D$ 作为内参时, 结果出现 了严重偏差. 此外, 本试验中稳定性较好的 $E f l \alpha$ 与 $\beta$-Actin 单独作为内参时其表达量之间差异相对较大, 
故选择两个内参基因可以有效地校正结果. 因此, 要 使定量结果更加准确, 需要设置多个内参基因. 印度 谷螟内参基因的篮选目前还未见报道, 需进行更广 泛深入地挖掘, 才能够获得更加理想的内参组合. 本
研究既为印度谷螟功能基因组学研究提供有用的 信息资源，也暗示开展印度谷蛽在不同实验条件下 的基因表达分析时，应仔细确认所选内参基因的稳 定性.

\section{参考文献}

1 Heid C A, Stevens J, Livak K J, et al. Real time quantitative PCR. Genome Res, 1996, 6: 986-994

2 Derveaux S, Vandesompele J, Hellemans J. How to do successful gene expression analysis using real-time PCR. Methods, 2010, 50: 227-230

3 VanGuilder H D, Vrana K E, Freeman W M. Twenty-five years of quantitative PCR for gene expression analysis. Biotechniques, 2008, 44: 619

4 Infante C, Matsuoka M P, Asensio E, et al. Selection of housekeeping genes for gene expression studies in larvae from flatfish using real-time PCR. BMC Mol Biol, 2008, 9: 1

5 Pombo-Suarez M, Calaza M, Gomez-Reino J J, et al. Reference genes for normalization of gene expression studies in human osteoarthritic articular cartilage. BMC Mol Biol, 2008, 9: 1

6 Radonić A, Thulke S, Mackay I M, et al. Guideline to reference gene selection for quantitative real-time PCR. Biochem Biophys Res Commun, 2004, 313: 856-862

7 Spinsanti G, Panti C, Lazzeri E, et al. Selection of reference genes for quantitative RT-PCR studies in striped dolphin (Stenella coeruleoalba) skin biopsies. BMC Mol Biol, 2006, 7: 1

8 Yan H Z, Liou R F. Selection of internal control genes for real-time quantitative RT-PCR assays in the oomycete plant pathogen Phytophthora parasitica. Fungal Genet Biol, 2006, 43: 430-438

9 Ohno M, Kida Y, Sakaguchi M, et al. Establishment of a quantitative PCR system for discriminating chitinase-like proteins: catalytically inactive breast regression protein-39 and Ym1 are constitutive genes in mouse lung. BMC Mol Biol, 2014, 15: 23

10 Dragon F, Gallagher J E G, Compagnone-Post P A, et al. A large nucleolar U3 ribonucleoprotein required for 18S ribosomal RNA biogenesis. Nature, 2002, 417: 967-970

11 Creppe C, Malinouskaya L, Volvert M L, et al. Elongator controls the migration and differentiation of cortical neurons through scetylation of $\alpha$-Tubulin. Cell, 2009, 136: 551-564

12 Coulson D T R, Brockbank S, Quinn J G, et al. Identification of valid reference genes for the normalization of RT qPCR gene expression data in human brain tissue. BMC Mol Biol, 2008, 9: 46

13 Cao S, Zhang X, Ye N, et al. Evaluation of putative internal reference genes for gene expression normalization in Nannochloropsis sp. by quantitative real-time RT-PCR. Biochem Biophys Res Commun, 2012, 424: 118-123

14 An Y, Reimers K, Allmeling C, et al. Validation of differential gene expression in muscle engineered from rat groin adipose tissue by quantitative real-time PCR. Biochem Biophys Res Commun, 2012, 421: 736-742

15 Van Hiel M B, Van Wielendaele P, Temmerman L, et al. Identification and validation of housekeeping genes in brains of the desert locust Schistocerca gregaria under different developmental conditions. BMC Mol Biol, 2009, 10: 56

16 Ponton F, Chapuis M P, Pernice M, et al. Evaluation of potential reference genes for reverse transcription-qPCR studies of physiological responses in Drosophila melanogaster. J Insect Physiol, 2011, 57: 840-850

17 Swapna, Priya, Rajarapu, et al. Validation of reference genes for gene expression studies in the emerald ash borer (Agrilus planipennis). Insect Sci, 2012, 19: 41-46

18 Fu W, Xie W, Zhang Z, et al. Exploring valid reference genes for quantitative real-time PCR analysis in Plutella xylostella (Lepidoptera: Plutellidae). Int J Biol Sci, 2013, 9: 792-802

19 Shen G M, Jiang H B, Wang X N, et al. Evaluation of endogenous references for gene expression profiling in different tissues of the oriental fruit fly Bactrocera dorsalis (Diptera: Tephritidae). BMC Mol Biol, 2010, 11: 76

20 Li R, Xie W, Wang S, et al. Reference gene selection for qRT-PCR analysis in the sweetpotato whitefly, Bemisia tabaci (Hemiptera: Aleyrodidae). PLoS One, 2013, 8: e53006

21 Cheng D, Zhang Z, He X, et al. Validation of reference genes in Solenopsis invicta in different developmental stages, castes and tissues. PLoS One, 2013, 8: e57718

22 Maroniche G A, Sagadín M, Mongelli V C, et al. Reference gene selection for gene expression studies using RT-qPCR in virus-infected 
planthoppers. Virol J, 2011, 8: 1-8

23 周世豪，李磊，符悦冠. 高温胁迫下瓜实蝇的内参基因笁选. 热带作物学报, 2016, 37: 131-135

24 Sun M, Lu M X, Tang X T, et al. Exploring valid reference genes for quantitative real-time PCR analysis in Sesamia inferens (Lepidoptera: Noctuidae). PLoS One, 2015, 10: e0115979

25 刘金泊，欧静，姚富姣，等. 磷化氢诱导下赤拟谷盗实时定量 PCR 内参基因的篎选. 农业生物技术学报, 2014, 22: 257-264

26 吴玉, 翟渊粉, 黄明霞, 等. 家虫常用内参基因稳定性分析及丝蛋白相关基因表达调控研究. 中国细胞生物学学报, 2013, 4: $423-431$

27 Teng X, Zhang Z, He G, et al. Validation of reference genes for quantitative expression analysis by real-time RT-PCR in four lepidopteran insects. J Insect Sci, 2012, 12: 60

28 Hoflehner E, Binder M, Hemmer W, et al. Thioredoxin from the indianmeal moth Plodia interpunctella: cloning and test of the allergenic potential in Mice. PLoS One, 2012, 7: e42026

29 Harrison P W, Mank J E, Wedell N. Incomplete sex chromosome dosage compensation in the indian meal moth, Plodia interpunctella, based on de novo transcriptome assembly. Genome Biol Evol, 2012, 4: 1118-1126

30 Lourenço A P, Mackert A, Cristino A D S, et al. Validation of reference genes for gene expression studies in the honey bee, Apis mellifera, by quantitative real-time RT-PCR. Apidologie, 2008, 39: 372-385

31 Scharlaken B, de Graaf D C, Goossens K, et al. Reference gene selection for insect expression studies using quantitative real-time PCR: the head of the honeybee, Apis mellifera, after a bacterial challenge. J Insect Sci, 2008, 8: 33

32 Choi M Y, Meer R K V, Shoemaker D, et al. PBAN gene architecture and expression in the fire ant, Solenopsis invicta. J Insect Physiol, 2011, 57: 161-165

33 Vandesompele J, De Preter K, Pattyn F, et al. Accurate normalization of real-time quantitative RT-PCR data by geometric averaging of multiple internal control genes. Genome Biol, 2002, 3: research0034.1-research0034.11

34 Andersen C L, Jensen J L, Ørntoft T F. Normalization of real-time quantitative reverse transcription-PCR data: a model-based variance estimation approach to identify genes suited for normalization, applied to bladder and colon cancer data sets. Cancer Res, 2004, 64: $5245-5250$

35 Livak K J, Schmittgen T D. Analysis of relative gene expression data using real-time quantitative PCR and the $2^{-\triangle \Delta C T}$ method. Methods, 2001, 25: 402-408

36 Bustin S A, Benes V, Garson J A, et al. The MIQE guidelines: minimum information for publication of quantitative real-time PCR experiments. Clin Chem, 2009, 55: 611-622

37 Chen I H, Chou L S, Chou S J, et al. Selection of suitable reference genes for normalization of quantitative RT-PCR in peripheral blood samples of bottlenose dolphins (Tursiops truncatus). Sci Rep, 2015, 5: 15425

38 Nakamura A M, Chahad-Ehlers S, Lima A L A, et al. Reference genes for accessing differential expression among developmental stages and analysis of differential expression of OBP genes in Anastrepha obliqua. Sci Rep, 2016, 6: 17480

39 Schaeck M, De Spiegelaere W, De Craene J, et al. Laser capture microdissection of intestinal tissue from sea bass larvae using an optimized RNA integrity assay and validated reference genes. Sci Rep, 2016, 6: 21092

40 符伟, 谢文, 张卓, 等. Bt 毒素诱导下小菜蛾实时定量 PCR 内参基因的笁选. 昆虫学报, 2012, 55: 1406-1412

41 Yang C, Pan H, Liu Y, et al. Stably expressed housekeeping genes across developmental stages in the two-spotted spider mite, Tetranychus urticae. PLoS One, 2015, 10: e0120833

42 岳秀利, 高新菊, 王进军, 等. 二玟叶螨内参基因的笁选及解毒酶基因的表达水平. 中国农业科学, 2013, 46: 4542-4549

43 Olsvik P A, Lie K K, Jordal A E O, et al. Evaluation of potential reference genes in real-time RT-PCR studies of Atlantic salmon. BMC Mol Biol, 2005, 6: 1

44 Schmid H, Cohen C D, Henger A, et al. Validation of endogenous controls for gene expression analysis in microdissected human renal biopsies. Kidney Int, 2003, 64: 356-360

45 吴学友. 转 $\mathrm{Bt}$ 基因稻谷对印度谷蛽生长发育的影响及其机理研究. 硕士学位论文. 南京: 南京财经大学, 2013 


\title{
Selection of reference genes in quantitative real-time PCR of Plodia interpunctella (Lepidoptera: Pyralidae)
}

\author{
TANG PeiAn ${ }^{1}$, ZHANG QiLin $^{2}$, XUE Hao $^{1} \&$ YUAN MingLong ${ }^{3}$ \\ 1 Collaborative Innovation Center for Modern Grain Circulation and Safety, College of Food Science and Engineering, Nanjing University of \\ Finance and Economics, Nanjing 210023, China; \\ 2 Evo-devo Institute, School of Life Sciences, Nanjing University, Nanjing 210023, China; \\ 3 State Key Laboratory of Grassland Agro-Ecosystems, College of Pastoral Agricultural Science and Technology, Lanzhou University, Lanzhou \\ 730020, China
}

Quantitative real-time PCR (qRT-PCR) is an important tool for studying gene expression, whereas selection of reliable reference genes (RGs) is the basis for obtaining accurate qRT-PCR results. Plodia interpunctella is an important stored-product pest with worldwide distribution. In this study, we screened out reliable RGs of $P$. interpunctella for different developmental stages and strains, and evaluated expression stability of eight candidate RGs by using two independent softwares (geNorm and NormFinder). The results indicated that the most stable expression RG was Efl $\alpha$ under different developmental stages, whereas $\beta$-Actin and Efl $\alpha$ showed the most stable expression for different strains. Expression pattern of a target gene (peroxidase, POD) exhibited significant discrepancies between different strains based on normalization of Efl $\alpha, \beta$-Actin, as well as the combination of these two genes, but no significant difference was found with $S D$ that was the least stability RG. Therefore, it is an essential step for evaluating stability of candidate RGs before qRT-PCR analyses for target genes, and accurate expression levels of target genes could be acquired based upon normalization of the most reliable RGs selected by experiments. These results will be helpful for better studying function of development-related and strain-specific genes in $P$. interpunctella, and provide valuable information for further selecting optional RGs in qRT-PCR analyses of this pest under other conditions.

Plodia interpunctella, stored-product pests, quantitative real-time PCR, gene expression, reference genes, stability evaluation

doi: 10.1360/N052016-00176 